Goldschmidt 2021 Abstract

https://doi.org/10.7185/gold2021.3510

\section{Mixing between chemically variable primitive basalts creates and modifies crystal cargoes}

\author{
DAVID A NEAVE ${ }^{1}$, PHILIPP BECKMANN ${ }^{2}$, OLIVIER \\ NAMUR $^{3}$, OLIVER SHORTTLE ${ }^{4}$, HARALD BEHRENS ${ }^{2}$ \\ AND FRANCOIS HOLTZ ${ }^{2}$
}

${ }^{1}$ The University of Manchester

${ }^{2}$ Leibniz Universität Hannover

${ }^{3}$ Katholieke Universiteit, Leuven

${ }^{4}$ University of Cambridge

Presenting Author: david.neave@manchester.ac.uk

The products of volcanic eruptions provide crucial insights into the chemical structure of Earth's mantle and the dynamic behaviour of magmatic plumbing systems. However, the true diversity of deep chemical variability is often erased from erupted records by mixing and crystallisation during magma ascent. Moreover, the impacts of mixing between similarly primitive yet chemically distinct magmas on crystal cargoes and magma dynamics remain highly uncertain despite the ubiquity of mixing-induced disequilibrium features in volcanic eruption products.

In order to investigate how mantle-derived chemical variability affects the phase equilibria of primitive oceanic basalts we performed high-pressure (300 MPa), high-temperature $\left(1140-1260^{\circ} \mathrm{C}\right) \quad$ crystallisation experiments on synthetic analogues of chemically extreme primitive basalts from the Reykjanes Peninsula of Iceland. These experiments reveal that magmas from enriched, recycled and potentially pyroxenitic sources maintain higher melt fractions during crystallisation than those from ambient and relatively depleted sources comprised of fertile lherzolite. This is because plagioclase saturates at much lower temperatures in $\mathrm{Na}$ - and $\mathrm{H}_{2} \mathrm{O}$-rich melts from enriched sources than it does in $\mathrm{Ca}$ - and $\mathrm{Al}$-rich melts from depleted ones. Erupted records of mantle chemistry may thus become systematically biased towards melts from recycled sources as magmatic evolution proceeds because enriched melts are fundamentally more likely to survive crustal processing than their depleted counterparts.

By performing magma-magma reaction experiments, we then investigated how chemically distinct but crystal-bearing primitive basalts respond to mixing under crustal conditions (300 $\mathrm{MPa}$ and $1190^{\circ} \mathrm{C}$ ). These experiments demonstrate that basaltic melts diffusively re-equilibrate over mm-lengthscales within hours to days, with different elements responding at rates commensurate with their different diffusivities. Importantly, the presence of modest crystal fractions does not appear to significantly affect the re-equilibration of melt compositions, despite the major effect that re-equilibration exerts over localised phase equilibria relations. In particular, we observes that the diffusive re-equilibration of $\mathrm{Al}$ triggered rapid plagioclase resorption within initially plagioclase-saturated portions of our experimental products. Plagioclase resorption in response to isothermal mixing between chemically variable magmas may thus play an underappreciated but potentially widespread role in both creating crystal cargoes by unlocking plagioclase-rich mushes and modifying them through resorption, (re-) crystallisation and solid-state diffusion processes. 